
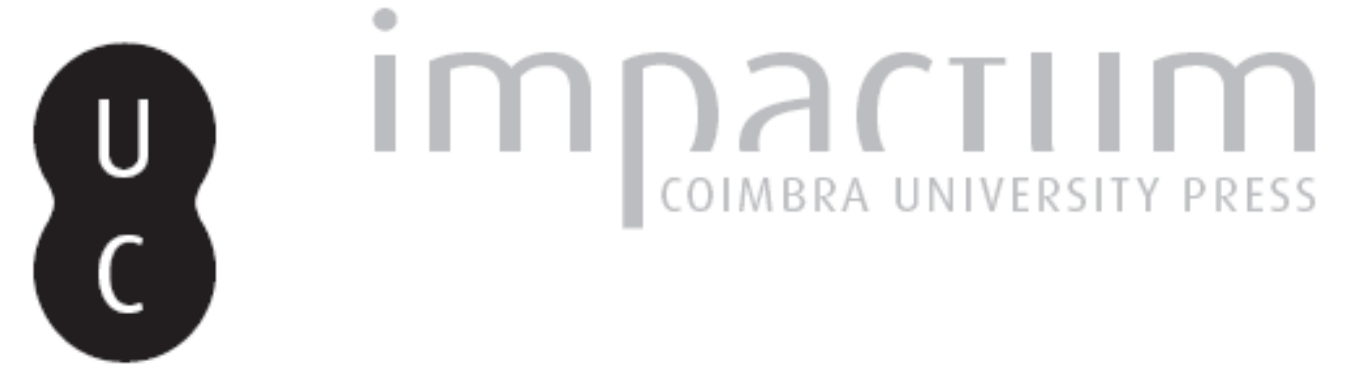

\title{
[Recensão a] D. P. S. Peacock e D. F. Williams, Amphorae and the Roman economy, an introductory guide
}

Autor(es): $\quad$ Fabião, Carlos

Publicado por: Imprensa da Universidade de Coimbra

URL persistente:

URI:http://hdl.handle.net/10316.2/45602

DOI:

DOI:https://dx.doi.org/10.14195/1647-8657_26_8

Accessed : $\quad$ 26-Apr-2023 11:32:10

A navegação consulta e descarregamento dos títulos inseridos nas Bibliotecas Digitais UC Digitalis, UC Pombalina e UC Impactum, pressupõem a aceitação plena e sem reservas dos Termos e Condições de Uso destas Bibliotecas Digitais, disponíveis em https://digitalis.uc.pt/pt-pt/termos.

Conforme exposto nos referidos Termos e Condições de Uso, o descarregamento de títulos de acesso restrito requer uma licença válida de autorização devendo o utilizador aceder ao(s) documento(s) a partir de um endereço de IP da instituição detentora da supramencionada licença.

Ao utilizador é apenas permitido o descarregamento para uso pessoal, pelo que o emprego do(s) título(s) descarregado(s) para outro fim, designadamente comercial, carece de autorização do respetivo autor ou editor da obra.

Na medida em que todas as obras da UC Digitalis se encontram protegidas pelo Código do Direito de Autor e Direitos Conexos e demais legislação aplicável, toda a cópia, parcial ou total, deste documento, nos casos em que é legalmente admitida, deverá conter ou fazer-se acompanhar por este aviso.

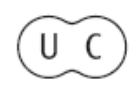


FACULDADE DE LETRAS

INSTITUTO DE ARQUEOLOGIA

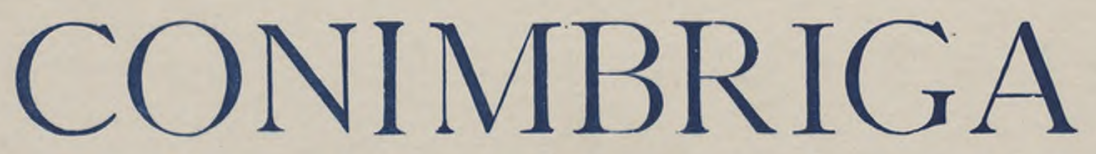

VOLUME XXVI

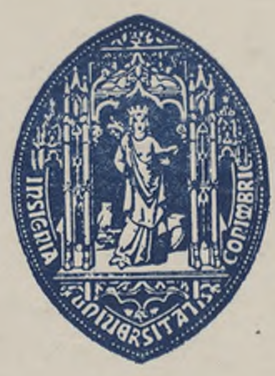

UNIVERSIDADE DE COIMBRA

1987 


\title{
RECENSÕES BIBLIOGRÁFICAS
}

\author{
D. P. S. Peacock e D. F. Williams, Amphorae and the Roman economy, an \\ introductory guide, Longman, London and New York, 1986, xix + 239 pp. \\ 139 figs.
}

A ânfora constitui o contentor típico para bens alimentares, destinados ao transporte e comércio por via marítima, na bacia do Mediterrâneo e regiões periféricas com ele relacionadas. Produzido e difundido no Crescente Fértil, ao que sabemos desde o II milénio a. C., conheceu no mundo romano, pelo menos desde os fins do séc. $\mathrm{m}$ a. C., diversos centros de produção, tornando-se num dos artefactos mais frequentemente encontrados pelos arqueólogos ñas diferentes áreas de influencia romana.

Embora não possuíssem a beleza das lucernas ou das cerâmicas finas, as ânforas foram recolhidas e incorporadas nas colecções de antiguidades clássicas desde época bastante recuada; e o facto de possuírem frequentemente marcas impressas, grafitos ou inscrições pintadas [tituli picti) conferiu-lhes um particular relevo no âmbito dos estudos epigráficos, encontrando-se ampiamente representadas no $\mathrm{CIL}$ - e mesmo na bibliografìa anterior. A atenção dos estudiosos, porém, recaía quase sempre exclusivamente sobre a inscrição, sem incluir qualquer descrição do artefacto que lhe servia de suporte. Neste particular reside a grande ambiguidade instalada no domínio do estudo das ânforas romanas: por um lado, como a esmagadora maioria destes contentores não possuía qualquer informação epigráfica, o seu estudo pertenceria simplesmente ao âmbito da ceramologia antiga; por outro, o facto de não patentearem o apuro formal ou a extrema regularidade das cerâmicas «finas» inibia os esforços de sistematização dos investigadores; finalmente, a esporádica presença das inscrições e letreiros, ou o seu amplo espaço de difusão e circulação conferia-lhes uma «dignidade» normalmente não atribuída às cerâmicas ditas de uso comum.

Penso que podemos definir diversas fase distintas nos progressos da investigação sobre ânforas romanas: uma primeira fase, onde se atendia exclusivamente às inscrições (marcas, grafitos ou tituli picti) não tomando em consideração a forma do artefacto onde estava feita e que se encontra eloquentemente expressa em quase todo o CIL; uma segunda fase, em que se 
nota uma crescente tentativa de relacionar a inscrição com a forma da ânfora sobre a qual se encontrava, bem expressa nos estudos de Schoene e Mau (CIL, IV (1 e 2) e, principalmente, de Dressel (Di un grande deposito di anfore rinvenuto nel nuovo quartiere del Castro Pretorio, in «Bulletino Comunale», 7, Roma, 1879, p. 36-112 e 143-196 e CIL XV (2)), autores das primeiras tabelas de formas.

A estes esforços pioneiros, segue-se uma longa fase onde se multiplicam desmesuradamente os achados de ânforas, na maioria dos casos sem qualquer informação epigráfica, publicando-se sucessivamente novas tabelas de formas, normalmente à razão de uma nova tabela por cada novo sítio extensamente escavado, como aconteceu com Haltern, Oberaden ou Camuludonum. Subsistindo o problema de não existir um suficiente conhecimento sobre os centros produtores que permitisse atribuir às diversas ânforas um lugar de origem, bem como todo um conjunto de dificuldades inerentes ao tratamento a dar aos pequenos fragmentos, registando-se uma natural sobrevalorização dos exemplares inteiros.

$\mathrm{Na}$ década de 50, o crescente interesse pela história económica e a multiplicação de sítios escavados conduziu a um processo de valorização de certos pormenores formais, tais como a forma do bordo, tipo de asas e seu encaixe, características do bico fundeiro, no sentido de poder utilizar proveitosamente a informação fornecida pelos fragmentos, até então frequentemente desprezados. As novas possibilidades da arqueologia subaquática contribuíram igualmente com um impressionante acervo de novos materiais, recolhidos em condições de jazida rigorosamente sincrónicos. Ensaiaram-se, ainda, as primeiras tentativas de identificação da proveniência das ânforas com base nas análises petrológicas das pastas. A esta fase encontram-se emblematicamente associados os nomes de Fernand Benoit e Nino Lamboglia, no Mediterrâneo Ocidental e Virginia Grace, no Mediterràneo Orientai.

Nos finais da década de 60 começou a delinear-se urna nova estratégia de estudo das ânforas com os trabalhos de D. P. S. Peacock, nos quais se ensaiava de modo sistemático a classificação das mesmas baseada na associação das particularidades formais, com as características petrológicas das pastas. A aplicação sistemática destas análises passaria a tornar possível a atribuição de proveniências, mesmo a partir de fragmentos incaracterísticos. Não é de estranhar, por isso, que os contributos do investigador britânico tenham sido já equiparados aos de H. Dressel, no desenvolvimento deste campo específico da arqueologia romana (v. P. R. SEALE Y, Amphoras from the 1970 excavations at Colchester Sheepen, BAR (B. S. 142), Oxford, 1985, p. 9).

Perante a multiplicação de sítios escavados, quer em «terra firme», quer submersos, bem como a desmesurada publicação de tabelas tipológicas, o processo de iniciação ao estudo das ânforas romanas tornou-se extremamente complexo e difícil. A presente obra cumpre, portanto, uma dupla função: por um lado, apresenta-se como um manual de introdução à problemática das ânforas romanas, que poupará certamente, no futuro, o espinhoso percurso de «iniciação» a qualquer interessado neste ramo da ceramologia romana; por 
outro, constitui o corolário de uma nova estratégia da investigação ensaiada desde os finais da década de 60, apesar de os autores não a apresentarem como tal.

A obra de Peacock e Williams constitui, assim, um contributo fundamental para o progresso da investigação e corresponde à ciclòpica tarefa de fornecer indicações para a identificação de boa parte das ânforas produzidas e difundidas em todo o Mundo Romano e periferias, desde o séc. m a. C., aos sécs. vu-vin d. C. Poucos investigadores poderiam ter a veleidade de meter ombros a uma tarefa desta envergadura; por isso, não se encontra o autor destas linhas minimamente habilitado para a criticar nos seus múltiplos aspectos. No entanto, a intenção desta recensão alongada é a de contribuir, em primeiro lugar, para a sua divulgação e, de algum modo, para o seu aperfeiçoamento futuro, visto que ela será, não o duvido, durante muitos anos, uma referência obrigatória. Para além de alguns comentários genéricos, centrarei a minha crítica nas questões que minimamente conheço, a saber: as produções do período republicano e as produções do actual território português.

A obra reparte-se por dois grandes blocos: uma primeira parte dividida em seis capítulos, consagrados a aspectos genéricos e uma segunda composta por um guia para a identificação das ânforas romanas mais comuns.

No prefácio esclarecem-se de forma sucinta os objecti vos da obra. Considerando o crescente interesse verificado pelo estudo das ânforas, como meio para a compreensão da economia romana e a extraordinária dispersão da informação disponível, os autores pretenderam apresentar uma introdução genérica e sintética - mas nem por isso menos rica - à problemática do estudo destes contentores cerâmicos. Apresentam os fundamentos da sua proposta de classificação, que conjuga as características formais dos artefactos, com as particularidades petrológicas das suas pastas, procurando, por este meio, fornecer um atestado de proveniência para cada uma das produções, tornando-as relevantes para uma efectiva análise económica. Tentam, igualmente, ao arrepio de uma tendência infelizmente generalizada nos estudos de ceramologia antiga do Mediterrâneo, articular a informação relativa à metade oriental do «mar interior», com a respeitante às zonas ocidentais.

No primeiro capítulo da primeira parte (p. 2-19) os autores traçam um breve historial das investigações sobre ânforas romanas, sintético e bem estruturado onde, no entanto, incorrem em alguns erros de pormenor. Por exemplo, depois de se referirem à publicação no CIL XV (2) da tabela de formas de Dressel, afirmam : «Despite this early and propositions start, amphorae were then virtually neglected until the middle of the century when a developing interest in underwater archaeology led Lamboglia (1950) and Benoit (1956) to considerer the subject anew...» (p. 3) incorrendo, em minha opinião, em duas omissões significativas. Em primeiro lugar, esquecem o labor dos investigadores do limes germânico, designadamente E. Loescke ou F. Schumacher, esquecem as propostas de F. Pélichet e esquecem, inclusivamente, o contributo dos seus compatriotas C. F. Hawkes e M. Hull, esquecimentos tanto mais estranhos, quanto vêm quase todos estes autores citados ao longo da obra, em outros 
contextos. Em segundo lugar, julgo ser incorrecto a associação de Lamboglia apenas à arqueologia subaquática, visto serem os seus trabalhos de Albintimilium (por sinal aqueles a que se reporta a citação que fazem) e Tindaris, ambos em sterra firme» que suscitaram o grosso das suas reflexões sobre a necessidade de rever as tipologías de ânforas romanas.

Parece-me igualmente incorrecto associar à tabela de Dressel publicada em 1909 no CIL XV(2) o início dos esforços de classificação tipológica das ânforas (p. 5-6), visto que a tabela relativa aos materiais de Pompeia, publicada por Schoene em 1898 no CIL IV (1), utilizada e acrescentada por Mau em 1905 no CIL IV (2), ou mesmo a publicação de Dressel do material de Castro Pretorio, em 1879, lhe são anteriores, embora a tabela do CIL XV (2) seja indiscutivelmente a mais precisa e completa.

$\mathrm{Na}$ esteira de Callender, os autores atribuem grande importância à capacidade de identificação da natureza do conteúdo das ânforas, pelos consumidores, proporcionada pela diversidade e padronização das formas, afirmando a título de exemplo: «(...) certain Roman forms seems to be imitating Greek amphorae previously made on the island of Kos, and presumably this was done because they contained Koan style wine made with sea water (...)» (p. 5). Tal afirmação, que constitui uma interessante sugestão para explicar aquilo a que C. Panella chamou a «revolução tipològica» ocorrida nos finais do séc. i a. C. nos centros produtores da costa ocidental da P. Itálica, esbarra, no entanto, com a dificuldade em admitir uma tão radical e generalizada mudança nos hábitos de produção e consumo. Acrescente-se que os próprios autores admitem, mais adiante (p. 24), uma hipótese bem mais plausível relacionada com aspectos funcionais, visto serem as ânforas deste novo tipo (Classe $10=$ Dr. 2-4) mais leves e de maior capacidade que as anteriores produções da mesma região, as ânforas Dr.-Lamb. I-B ( = Classe 4).

Ainda neste capítulo, os autores explanam a proposta de classificação que norteou o catálogo apresentado na segunda parte e que, embora seja merecedora de um comentário, tratarei na discussão dos aspectos concretos do guia.

No segundo capítulo (p. 20-30) abordam de forma igualmente sintética a história dos contentores cerâmicos do Mediterrâneo, desde os «jarros cananeus»e seus sucedâneos, até à progressiva substituição, na época medieval, pelos tonéis de madeira, não descurando, inclusivamente, algumas «sobrevivências», tais como os pequenos contentores de azeite pós-medievais da Andaluzia (a que E. Borges Garcia chamava «anforetas de iluminação» atribuindo-os erradamente à época romana) e mesmo algumnas produções actuais do Norte de África. Assinale-se apenas a contradição expressa na afirmação de que as ânforas Lamb. 2 se destinavam ao transporte de azeite, se bem que algumas vezes pudessem transportar vinho íp. 25), com a afirmação contrária, transporte de vinho, eventualmente azeite na p. 100, recorrendo-se para fundamentar a segunda, à evidência existente sobre o conteúdo destas produções, toda ela sugerindo um conteúdo vínico.

No terceiro capítulo (p. 31-43) analisam as relações entre o fabrico de ânforas e a produção de alguns alimentos destinados a nelas serem 
transportados, tais como o vinho, o azeite e os preparados piscícolas. Abordam em primeiro lugar as principais características da produção destes alimentos, referindo-se seguidamente aos modos de prover de ânforas os diversos centros produtores, frisando as numerosas possibilidades existentes, desde a autosuficiência da própria unidade produtora, passando pela especialização no fabrico de contentores, eventualmente circunscrito a algumas unidades que, desse modo, se auto-abasteciam, provendo, também, as explorações que lhe eram vizinhas, à possibilidade da existência de oleiros independentes, vinculados, ou não, ao centro produtor. Anote-se a extrema prudência dos autores no tratamento desta questão, não deixando de admitir a existência de outras possibilidades, bem como o facto dos diversos regimes de produção não se excluírem. Isto é, existem fortes probabilidades de terem coexistido. Neste capítulo, são por demais notórias as intransponíveis dificuldades de compreensão dos processos produtivos que advêm da quase total ausência de investigações específicas sobre os centros produtores de ânforas.

No capítulo quarto (p. 44-53), debruçam-se sobre os aspectos concretos do fabrico das ânforas romanas, numa excelente abordagem onde surgem perfeitamente articuladas as informações colhidas da investigação arqueológica, com as observações de carácter etnográfico, realizadas em diversos locais da bacia do Mediterrâneo onde actualmente ainda se fabricam contentores cerâmicos de grandes dimensões, culminando numa interessante análise sobre os graus de eficácia dos diversos tipos de ânfora, no transporte de bens alimentares, expresso na proporção entre o volume do contentor e o seu peso vazio.

O capítulo quinto (p. 54-66) é consagrado às questões relacionadas com o comércio e transporte. Partindo da já clássica sistematização de Karl Polany sobre as formas de intercâmbio nas sociedades antigas, aqui enriquecido com alguns contributos mais recentes da investigação etno-arqueológica e sociológica, os autores apresentam uma boa síntese sobre o estado dos conhecimentos relativos a estes mecanismos no mundo romano, demonstrados com exemplos pertinentes, lançando algumas pistas de trabalho que poderão vir a revelar-se fecundas. Uma vez mais, combinam com mestria informações provenientes de fontes diversificadas, recorrendo, neste caso, aos dados contidos nas fontes literárias clássicas, à evidência arqueológica e epigráfica disponível, articuladas com as construções teóricas de antropólogos, economistas e historiadores da economia.

O capítulo sexto (p. 67-77) apresenta um inventário dos fornos de ânforas conhecidos em todo o mundo romano e merece alguns comentários. Em primeiro lugar, os autores contrariam a associação, proposta por A. Tchernia, das ânforas com marca M. TYCCI. LF. TRO / GALEONIS, recolhidas no naufrágio Planier 3, às produções de Brindisi, invocando o não aparecimento de qualquer marca daquele tipo neste local, embora reconheçam a semelhança formal - julgo que se pode acrescentar, também, a coincidência das áreas de distribuição (v. CIL I (2) n. ${ }^{\circ}$ 2654) — alegando, ainda, o facto de apresentar, o exemplar destas produções que estudaram, uma pasta característica da zona 
da Campânia (p. 68-9). Ora, se assim é, julgo que se impunha a abertura de uma nova categoria para estas produções campanienses, no guia apresentado na segunda parte, ou, no mínimo, o reconhecimento de um fabrico centro-itálico dentro da Classe $1 . .$.

No respeitante ao actual território português, o panorama dos fornos apresentado é extremamente pobre visto que, aparentemente, os autores consultaram apenas o artigo de A. PARKER, Lusitanian amphoras e os textos por ele citados, ou seja, o artigo de Leite de Vasconcelos, Olaria luso-romana de S. Bartolomeu de Castro Marim e o de F. Almeida, G. Zbyszewsio e O. Veiga Ferreira, Descoberta de fornos Lusitano-Romanos na região de Marateca (Setúbal), ignorando, inclusivamente, o forno de S. João da Venda (Faro), que Parker refere. É já apreciável a quantidade de informação sobre fornos e centros de produção no actual território português - se bem que na sua maioria proveniente de recolhas de superfície - encontrando-se boa parte publicada há já algum tempo, não tendo sido, porém, considerada pelos autores. Torna-se, por isso, urgente chamar a atenção dos investigadores britânicos para o trabalho já realizado pelos arqueólogos do extremo ocidental da Península Ibérica, nomeadamente por: Guilherme Cardoso, C. Tavares da Silva, A. Coelho-Soares ou A. M. Dias Diogo, com vista à revisão de toda a informação relativa ao actual território português, numa futura edição.

A segunda parte do Amphorae and the Roman Economy é composto pelo guia para a identificação das ânforas romanas de ampla difusão, mais comuns. É justamente aqui que reside a crucial importância desta obra, visto apresentar-se uma nova estrutura de classificação para estes materiais, embora, modestamente, os autores não a apresentem como tal. No entanto, atendendo às crescentes dificuldades levantadas pela multiplicação de tipologías regionais, julgo que esta nova proposta poderia começar a ser encarada como uma nova sistematização de utilização universal.

Os autores definem, no primeiro capítulo, as normas da sua classificação, sublinhando que só podemos falar de tipos quando se define uma relação de identidade de forma e fabrico pelo que esclarecem, a título de exemplo: «(...) our amphora 10 (= Dr. 2-4) is a class within which it is possible to distinguish Campanian and Catalan types. In general, it is best to regard all our groups as Classes which, with further research, may be decided into types on the basis of both fabric and nuances of form.» (p. 9). Contudo, os autores não propõem formas de desenvolvimento das suas Classes. Isto é, não esclarecem de que modo devemos começar a acrescentar novas classes... Não esclarecem igualmente de que modo se deve proceder para decompor em tipos cada uma das classes. Em alguns casos não sugerem qualquer decomposição, apesar de existirem argumentos suficientes para o fazerem, noutros, fazem-no recorrendo a uma designação toponímica, enquanto que em outros casos, ainda, utilizam um numeral de referência.

Vejamos algumas objecções que julgo pertinentes:

a) Por que razão aparecem separadas as ânforas da Classe 1 (ânforas de Brindisi, ou Baldacci I) (p. 82-3) das ânforas Lamboglia 2, ou Baldacci 
11, igualmente produzidas na Apúlia ?... E por que razão estas surgem agrupadas numa mesma Classe, a 8 , com as produções istrianas da forma Dressel 6 ? Parece-me que deste modo não só se segmentou uma importante tradição regional de produção de contentores, como se produziu um agrupamento desaconselhável, quer pelas diferenças morfológicas dos artefactos, quer, principalmente, pelas diferenças de cronologia dos dois tipos...

b) No respeitante à Classe 2 (ânforas chamadas «greco-itálicas») (p. 84-5) por que razão não se aceitou, de facto, a subdivisão proposta por E. L.Will que até é referida no texto?...

c) Por que razão se subdividiu a Classe 3 (Dressel/Lamboglia 1-A) (p. 86-8) em fabrico (simplesmente) e fabrico companiense, enquanto que as Classes 6 ou 9 se subdividem, de forma bastante mais cómoda, em fabricos 1 e 2 ?

d) No respeitante à Classe 8 (P. 98-101) v. o que acima se disse.

e) Atendendo à perspectiva em que os autores se colocam - tentar fornecer informações úteis para o estudo da economia e comércio do Império Romano - parece-me um contra-senso agrupar numa mesma categoria, a Classe 10 (Dressel 2-4) (p. 105-6), todo um conjunto de ânforas que, embora patenteiem características formais análogas , conheceram centros de produção tão diferenciados como a Península Itálica, o sul da Gália, a Catalunha, a Bética e, presumivelmente, a Grã-Bretanha... Uma vez mais surge a designação toponímica para identificar os diversos fabricos, neste casos, só merecendo descrição o Campaniense e o Catalão.

f) Da mesma forma que levantam a possibilidade — por sinal já confirmada (v. Comas i Soud, Baetulo: les Amfores, Monografias Badalonines 8, Badalona, 1985, particularmente as p. 65-6) - da existência de diversos tipos dentro da Classe 6 (Pascual 1) (p. 95), julgo que o deveriam ter feito em relação aos exemplares que ilustram a Classe 14 (Dressel 12, Beltrán III) (p. 113-4), suficientemente distintos para justificarem idêntica afirmação.

g) No respeitante à Classe 15 (Haltern 70) (p. 115-6), é, a meu ver, discutível e leviana a referência a uma pretensa «unusually small variani» (p. 115) dentro desta Classe, visto ser fortemente plausível que esta «variante grácil» tenha constituído uma das primeiras produções anfóricas, de influência romana, da zona meridional da Península Ibérica, suficientemente distinta da típica Haltern 70, com a qual mantém, no entanto, semelhanças no perfil do lábio e no sulco longitudinal das asas, o que coloca naturais dificuldades à classificação de fragmentos de pequenas dimensões. Poderão ter pertencido a esta «variante» os exemplares já publicados de: Ampúrias, acampamentos $\mathrm{Y}$ de Renieblas e de Castillejo (Numantia), naufrágio de Palamós, depósito de Zaragoza e, eventualmente, muitos outros normalmente classificados como «ânforas ovoides republicanas». 
h) A significativa variação formal verificada entre os exemplares da Classe 16 (Dressel/Zevi 7-11, Beltrán I) (p. 117-9) justificava uma subdivisão - tão relevante quanto a efectuada de há longa data para a Dressel 1 - à semelhança do que o próprio Beltrán Lloris já propôs (v. Las anforas romanas de salazones de la Forma /, variante b, de la Betica, in: «Homenage al Prof. Martin Almagro Basch», IV, Madrid, 1983, p. 43-52).

i) A divisão estabelecida entre a Classe 20 (Dressel 14, Beltrán IV-a) e a Classe 21 (Beltrán IV-b) (p. 126-9) não se justifica. Os autores apresentam, de facto, dois exemplares completamente distintos, para ilustrar as produções da Bética e da Lusitânia; no entanto, essa diversidade morfológica é mais aparente que real, visto terem os centros de produção do vale do Sado, fabricado formas análogas às dos fornos de Granada. As lacunas de informação respeitantes ao actual território português são particularmente notórias na ficha da Classe 21 (p. 128-9)...

j) Constitui uma lacuna signicativa a inexistência de uma entrada para as ânforas da forma Almagro 51 a-b (Beltrán 52), identificadas e classificadas desde a escavação das necrópoles de Ampúrias e que foram produzidas na Lusitânia, pelo menos, nos fornos da quinta da Alegria (Setúbal) e S. João da Venda (Faro).

k) Não se compreende a razão da inclusão das três variantes definidas por Van den Werff para a forma Dressel 18 (= Neo-púnica, ou Mañá C 1 e 2) numa única categoria, a Classe 32 [p. 151-2)...

Poder-se-ia também lamentar algumas ausências, designadamente a das produções de Ibiza estudadas por Juan Ramon (La producción anforica punicoebusitana, Eivissa, 1981), algumas já de clara influência romana, nomeadamente os tipos PE-23, PE-24, PE-25 e PE-26...

Quase todas as Classes são apresentadas em desenho e fotografia, acompanhados, na maioria dos casos, por fotografias ao microscópio realçando a composição das pastas. A ficha descritiva de cada uma inclui pequenos textos sucintos sobre as particularidades formais, os centros produtores, as áreas de distribuição, os principais conteúdos, o âmbito cronológico e os diversos fabricos conhecidos, apresentando-se, ainda, as suas características observáveis em exame macroscópico («visual characteristics») e a composição das pastas («petrological characteristics»).

A obra inclui, para além das 55 Classes apresentadas, um conjunto de 10 potenciais novas Classes (56 a 66, p. 212-17) que, no entanto, os autores apresentam ainda a título provisório, visto não terem podido aprofundar devidamente o estudo de cada uma delas.

Como apêndice apresenta-se uma utilíssima lista de concordâncias entre a nova classificação e as diversas designações anteriormente existentes, quer as resultantes de tabelas tipológicas regionais, quer as incluídas nas anteriores classificações «universais». 
Completam a obra um índice geral e uma abundante e rica bibliografia.

Pese embora o eventual «excesso» de reparos feitos, as características que revestem o trabalho de Peacock e Williams, principalmente as normas de classificação propostas e a excelente apresentação de cada Classe, tornam-no em obra fundamental para os estudiosos de ânforas romanas, em particular, e de economia antiga, em geral, constituindo indiscutivelmente um marco na história da investigação anfórica; para além de suprir de forma exemplar uma importante lacuna existente na bibliografia arqueológica, fornecendo um magnifico manual introdutório ao estudo destes artefactos.

\section{CARLOS FABIÃO}

Dali Colns, U épave de la Colonia de Sant Jordi 1 [Majorque). Publications da Centre Pierre Paris et du Centre d'Études et de Recherches Archéologiques Sous-Marines. Paris, Diffusion de Boccard, $1987 . \quad 1$ vol., 118 p., 15 figs., 3 cartas, 21 estampas de desenhos +12 de fotografias.

Colonia Sant Jordi é um pequeno porto de pesca na ilha de Maiorca, abrigado numa baía onde se encontram vestígios de embarcações antigas naufragadas. Segundo D. Cerdà, os naufragados corresponderiam a oito embarcações. As prospecções efectuadas por D. Colls levam este autor a reduzir os oito naufrágios apenas a três. A presente monografia publica um deles: o de uma embarcação de cerca de 27 toneladas, com 11 a 13 metros de comprimento. $\mathrm{O}$ anterior estudo de $\mathrm{D}$. Cerdà sobre o mesmo assunto fica ultrapassado por este trabalho, no qual o autor justa mas discretamente reivindica o mérito científico que lhe coube na exploração deste naufragado.

Apesar da modéstia dos meios técnicos de que D. Colls poder dispor e da considerável destruição do barco, o cuidado com que o autor observou os vestígios permitiu-lhe a reconstituição da técnica construtiva da embarcação. D. Colls descreve minuciosamente os diferentes elementos de madeira e de metal do casco e reconstitui a sua articulação e montagem. A técnica construtiva é diferente de outras até agora reconhecidas em naufragados antigos. $\mathrm{Na}$ sua aparente modéstia, este estudo de D. Colls é, por conseguinte, um contributo valioso para a história da tecnologia naval na Antiguidade.

Os materiais cerâmicos recuperados incluem ânforas (54 peças identificáveis), campaniense (28 peças), cerâmica comum e alguns outros tipos escassamente representados, como taças com decoração em relevo, lucernas, cerâmica de paredes finas, almofarizes. Do estudo destes materiais, o autor deduz a cronologia do naufrágio: 100-80 a.C.

$\mathrm{O}$ autor sugere que a ilha de Maiorca foi simples porto que a embarcação procurou para fazer escala, mais do que para comerciar. O naufrágio, que surpreendeu a equipagem na baía de Sant Jordi, poderá ter sido provocado

\section{Conimbriga, 26 (1987), 167-180}

